\title{
Effect of 3D Printing Technology on 3C Product Manufacturing
}

\author{
Guangqing Shang1, Chunhua Sun ${ }^{2 *}$ \\ ${ }^{1}$ College of Electronic Information Engineering, Suzhou Vocational University, Suzhou, China \\ ${ }^{2}$ Department of Mechanic and Electronic Engineering, Suzhou Vocational University, Suzhou, China \\ Email: shanggq@jssvc.edu.cn, *chh_sunny@163.com
}

How to cite this paper: Shang, G.Q. and Sun, C.H. (2020) Effect of 3D Printing Technology on 3C Product Manufacturing. World Journal of Engineering and Technology, 8, 712-719.

https://doi.org/10.4236/wjet.2020.84051

Received: September 15, 2020

Accepted: November 6, 2020

Published: November 9, 2020

Copyright () 2020 by author(s) and Scientific Research Publishing Inc. This work is licensed under the Creative Commons Attribution International License (CC BY 4.0).

http://creativecommons.org/licenses/by/4.0/

(c) (i) Open Access

\begin{abstract}
$3 \mathrm{D}$ printing technology, as one of the most subversive technologies in the 21st century, processes the entity through layer by layer superposition. It breaks through the design constraints and adapts to customized production with high flexibility, which is an important direction of industrial development in the future. $3 \mathrm{C}$ product has a very board application market and groups, so it has been widely valued over the world. The advantages of 3D printing technology are very suitable for the characteristics of $3 \mathrm{C}$ product, such as diversification, small-volume, personalized. Here, the impact of 3D printing technology on manufacturing industry is firstly discussed; $3 \mathrm{C}$ product manufacturing system integrated with $3 \mathrm{D}$ printing is finally put proposed. The advantages of the proposed system possess shorter manufacturing cycle, supply chain and logistics. It makes easier to realize personalized 3C product, localized manufacturing and reduce cost. The development and wide application of $3 \mathrm{D}$ printing technology in $3 \mathrm{C}$ product industry will make the manufacture of low-cost small batch or even individual customized products into a general mode towards the trend of "light luxury + light customization".
\end{abstract}

\section{Keywords}

3D Printing, Additive Manufacturing, 3C Product, Manufacturing System

\section{Introduction}

3C product is the abbreviation of computer, communication and consumer electronic products, including mobile phone, personal computer, tablet computer, intelligent wearable device, digital camera, etc. 3C product covers a wide range of products, which have a series of commonness of large output, fast update. The manufacturing process of $3 \mathrm{C}$ product involves many links and the 
process flow is complex [1]. Therefore, many countries and regions attach great importance to $3 \mathrm{C}$ product manufacturing industry. 3C product manufacturing industry is a more popular one of intelligent application and promotion. In China, many $3 \mathrm{C}$ product manufacturing enterprises have become the national intelligent manufacturing demonstration pilot, and have constructed some new manufacturing modes that can be used for reference. However, due to the fact that the whole manufacturing of $3 \mathrm{C}$ products is oriented to mass production, it is difficult to meet people's demand for personalized, low-cost and fast updating products.

$3 \mathrm{D}$ printing, also named as additive manufacturing, is a subversive new technology, in which 3D model is discretized into two-dimensional sliced surface information, and then the three-dimensional entity is produced via superposition layer by layer. This innovative method is a kind of calculus manufacturing, which can control the shape and performance from the meso and micro level of materials to realize digital manufacturing in the whole process [2]. Due to the characteristics of $3 \mathrm{D}$ printing, it breaks through the limitation of subtractive manufacturing (turning, milling, grinding, etc.) and equivalent manufacturing (forging, casting, stamping, etc.). 3D printing can produce any complex and any shape products in any field with cost independent of batch size in any place [3]. This unique advantage of 3D printing has been well reflected during this year's epidemic, and has become an important part of the supply chain of world epidemic prevention system [4].

$3 \mathrm{D}$ printing is especially suitable for the processing of small batch products and can also boost the low-cost personalized customization of products, so it is especially suitable for the manufacturing of $3 \mathrm{C}$ product. At present, research of influence of $3 \mathrm{D}$ printing on global manufacturing is not much [5]. Compared with other research fields, the part of the research is seriously lacking. Therefore, it is necessary to strengthen research in this field. The purpose of this paper is to discuss effect of $3 \mathrm{D}$ printing technology on 3C product, including design and manufacturing. The structure of the paper lists following: this part mainly describes the characteristics of $3 \mathrm{C}$ products and $3 \mathrm{D}$ printing; the second part will describe impact of $3 \mathrm{D}$ printing on manufacturing; the third part will discuss the change of $3 \mathrm{C}$ product manufacturing system after integrating of $3 \mathrm{D}$ printing technology; and the last is summary.

\section{Effect of 3D Printing Technology on Manufacturing Industry}

The emergence of any technology is due to needs of the society, and the transformation of any enterprise is to adapt to changes of the market. 3D printing is a kind of principle innovation, which brings new opportunities and many possibilities for companies which are seeking to improve manufacturing efficiency. This technology provides designers with full freedom, so that the design is no longer limited to manufacturing, and fully releases the designer's imagination [6]. Therefore, some lattice structure, integrated structure and topology optimization structure, as shown in Figure 1, have obtained innovative applications. 


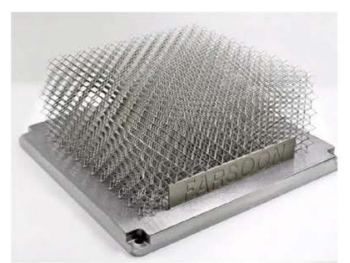

(a)

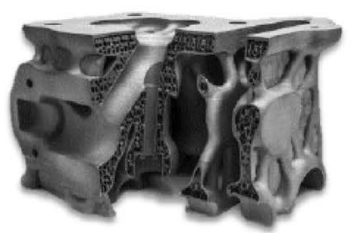

(b)

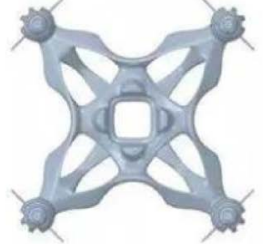

(c)

Figure 1. Innovation structure via additive manufacturing. (a) Lattice structure; (b) Integrated structure; (c) Topology optimization structure.

With 3D printing, the cost of small batch, even single and complex piece and personalized customized products can be maintained at a low level, as shown in Figure 2 [7]. Because of this, the manufacturing mode of low-cost products will no longer be obtained only through mass production in the future.

3D printing has been applied in many fields, from key applications such as aircraft parts and medical devices to common highly engineering products, such as running shoes. At present, more than $20 \%$ of the $3 \mathrm{D}$ printing market consists of parts in the aerospace and automotive industries [8]. In 2013, more than 22000 parts were manufactured in the aerospace industry via 3D printing [9]. The success and growth level of 3D printing in these industries shows that $3 \mathrm{D}$ printing technology is no longer the technical level of printing prototype, and the quality level of $3 \mathrm{D}$ printing components has met the strict industry standards. It is expected that it will completely change many niche areas and is expected to see exponential growth [10]. It is estimated that 3D printing will be more widely used in less than 10 years. However, 3D printing will not replace the existing production methods such as subtractive manufacturing and equal manufacturing. 3D printing will cooperate with various manufacturing modes and promote each other to make the manufacturing process more democratic [11]. Table 1 lists the impact of 3D printing on manufacturing industry.

In addition, 3D printing has a great impact on the whole supply chain and logistics of products, and has gradually become a valuable method to improve efficiency of the supply chain. According to some academic studies, 3D printing has great potential in reducing complexity of the supply chain [12]. One advantage of $3 \mathrm{D}$ printing technology is that it can print any kind of complex parts which make some components integrate into a product, so then assembly and pre-assembly may be cancelled. Further supply chain nodes and inventory complexity and operating costs are reduced. At the same time, 3D printing makes it possible to customize products individually. Therefore, 3D printing will have a significant impact on the logistics and inventory sectors. Through the participation of customers in design and manufacturing, even sales, the distance between customers and manufacturing enterprises is shortened. It makes enterprises rapidly response to market changes for reducing operating costs and increasing profits.

As a result, this technology can transform the global supply chain into a globally connected but fully localized supply chain, which allows some goods 


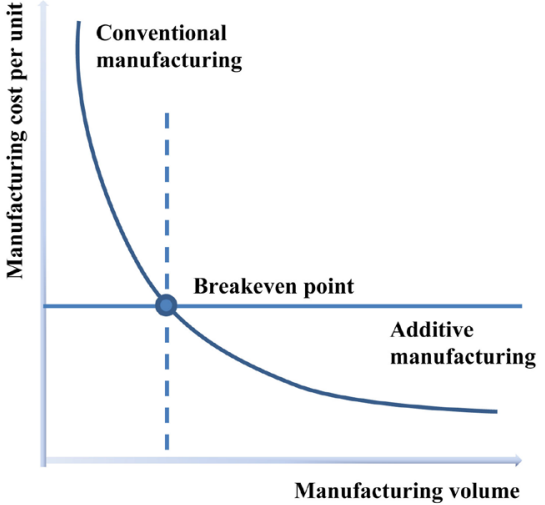

(a)

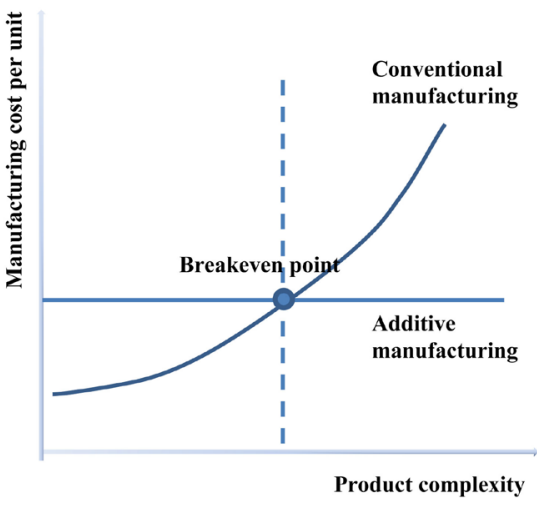

(b)

Figure 2. Cost comparison of $3 \mathrm{D}$ printing with conventional manufacturing. (a) Cost via manufacturing volume; (b) Cost via product complexity.

Table 1. Impact of 3D printing on manufacturing.

\begin{tabular}{|c|c|}
\hline Manufacturing Improvement & Key Enabling Capabilities \\
\hline \multirow{3}{*}{ Industrial Efficiency } & $\diamond$ Reduce material inputs for leaner manufacturing \\
\hline & $\begin{array}{l}\diamond \quad \text { Multi-material capability; ability to print complete } \\
\text { systems or subsystems }\end{array}$ \\
\hline & $\diamond$ Simplify production process, reducing costs \\
\hline Mass Customization and & $\diamond$ Customization to consumer requirements at low cost \\
\hline \multirow[t]{2}{*}{ On-demand Manufacturing } & $\diamond \quad$ Low cost of increased complexity \\
\hline & $\diamond$ Manufacturing is moving closer to the consumers \\
\hline \multirow{2}{*}{ Decentralized Manufacturing } & $\diamond \quad$ Manufacturing at point of use \\
\hline & $\begin{array}{l}\diamond \text { Consumers print their own spare parts for fixing } \\
\text { their personal item }\end{array}$ \\
\hline \multirow{2}{*}{ Small Volume Manufacturing } & $\diamond$ Small batches can be produced cost-efficiently \\
\hline & $\diamond \quad$ Eliminate the investment in tooling \\
\hline \multirow{3}{*}{ Rapid Prototyping } & $\diamond$ Reduce time-to-market by accelerating prototyping \\
\hline & $\diamond$ Reduce the cost involved in product development \\
\hline & $\begin{array}{l}\diamond \text { Making companies more efficient and competitive } \\
\text { at innovation }\end{array}$ \\
\hline \multirow{3}{*}{ Machine Tool Manufacturing } & $\diamond$ Reduce labor cost \\
\hline & $\diamond$ Avoid costly warehousing \\
\hline & $\diamond$ Enables mass customization at low cost \\
\hline \multirow{2}{*}{ Impact on Environment } & $\diamond \quad$ Improve sustainability \\
\hline & $\diamond$ Less negative impact on environment \\
\hline \multirow{6}{*}{ Quality Improvement } & $\diamond$ Simplify production processes, reducing costs \\
\hline & $\diamond \quad$ Shorter manufacturing lead time \\
\hline & $\diamond$ Lower risk by providing a contingency plan \\
\hline & $\diamond$ Quick reaction to change in demand \\
\hline & $\diamond$ Better management of demand uncertainty \\
\hline & $\diamond$ Improve process flexibility \\
\hline
\end{tabular}

originally produced in other countries to be locally manufactured. And mass customization products also reduce the demand for inventory and warehouse. The long-term large-scale production economy will give way to limited custo- 
mization production, and the original "push supply chain" mode will transform into "pull supply chain".

\section{3C Product Manufacturing Integrated with 3D Printing}

3D printing has deeply been affecting the whole manufacturing industry, fundamentally changing the way of product manufacturing. According to a recent study, 3D printing is the technology of best suited for small volume, customer specific, and affordable products, which require a high degree of customization and a short lead time to bring them closer to the consumer group. On the other hand, 3D printing can use more kinds of materials, such as metal, plastic, nylon, etc. These characteristics coincide with manufacturing $3 \mathrm{C}$ products. The application of 3D printing technology will bring the following changes to $3 \mathrm{C}$ product manufacturing industry: 1) Simplification of production process, 2) Customized service on-line, 3) More complex design, 4) Digital platform mode.

$3 \mathrm{D}$ printing serves $3 \mathrm{C}$ products via two ways: indirect manufacturing and direct manufacturing [13]. Indirect manufacturing actually follows the traditional injection molding or stamping process of $3 \mathrm{C}$ products, 3D printing is used to manufacture investment mold for injection or stamping. The available 3D printing processes include SLA, DLP technology based on photopolymerization process, and project based on ink-jet technology. The powder bed selective laser melting 3D printing equipment directly forming metal, FDM molding plastic products or SLA molding nylon are used to directly manufacture 3C products. Direct manufacturing, compared to indirect manufacturing, does not need mold and makes the manufacturing process further shorten. In addition, the direct manufacturing process can achieve very complex geometric structure, even the structure that cannot be realized by injection molding or stamping process. This creates conditions for $3 \mathrm{C}$ product design freedom to enhance again.

However, the direct manufacturing is not the manufacturing mode which widely accepted by $3 \mathrm{C}$ product manufacturing industry. The reason is that the surface precision and smoothness of $3 \mathrm{C}$ products via direct manufacturing process are difficult to compare with those of injection molding and mechanical processing. The post-processing is required after 3D printing, which virtually increases the difficulty of manufacturing. On the other hand, direct manufacturing process requires high purity and particle size of metal materials, which makes the cost of metal direct printing high.

Whether it is direct manufacturing or indirect manufacturing, compared with the traditional process, 3D printing reduces the manufacturing steps of 3C product and improves the productivity significantly. Meanwhile, 3D printing reduces the dependence on manual experience. This facilitates the production and quality management of $3 \mathrm{C}$ product processing enterprises.

Although the customization of $3 \mathrm{C}$ products is not a new service after the emergence of 3D printing technology, the born digital advantages of 3D printing technology make small batch customization production more advantageous in cost and efficiency, which can bring more convenient conditions for $3 \mathrm{C}$ product 
customization. At the same time, the digital characteristics of 3D printing make it have the "gene" of Internet, thus creating conditions for the combination of $3 \mathrm{C}$ product customization service and the Internet. Based on the above discussion, $3 \mathrm{C}$ product manufacturing industry integrated with $3 \mathrm{D}$ printing will form a new manufacturing mode as shown in Figure 3, which combines 3D printing with multiple manufacturing.

On the proposed $3 \mathrm{C}$ product service platform, three partners among consumers, designers and brands will share big data and exchange and communicate product data through the Internet. Only after the consumer has determined the design scheme can the production be carried out. Therefore, the integration of $3 \mathrm{D}$ printing into the manufacturing of $3 \mathrm{C}$ products is not only the improvement of manufacturing technology, it will affect the existing product customization and sales mode, and make consumers change from simple product buyers to "designers".

On this platform, consumers who were originally in the downstream may put forward personalized requirements and participate design process in the upstream. Driven by the personalized needs of consumers and supported by the Internet, big data and information technology, $3 \mathrm{C}$ industry will develop towards the trend of "light luxury + light customization" [14].

$3 \mathrm{D}$ printing can help $3 \mathrm{C}$ product manufacturing industry to realize the transformation from single variety (small variety) mass production mode to multi variety, small batch or multi variety and multi batch production mode as soon as possible. This is the foothold of 3D printing technology in 3C product, which can better reflect the technical characteristics of 3D printing and meet the market demand of $3 \mathrm{C}$ products and the fierce market competition.

\section{Summary}

With the improvement of science and technology level, people put forward higher requirements for $3 \mathrm{C}$ products in terms of high quality, individuation, low

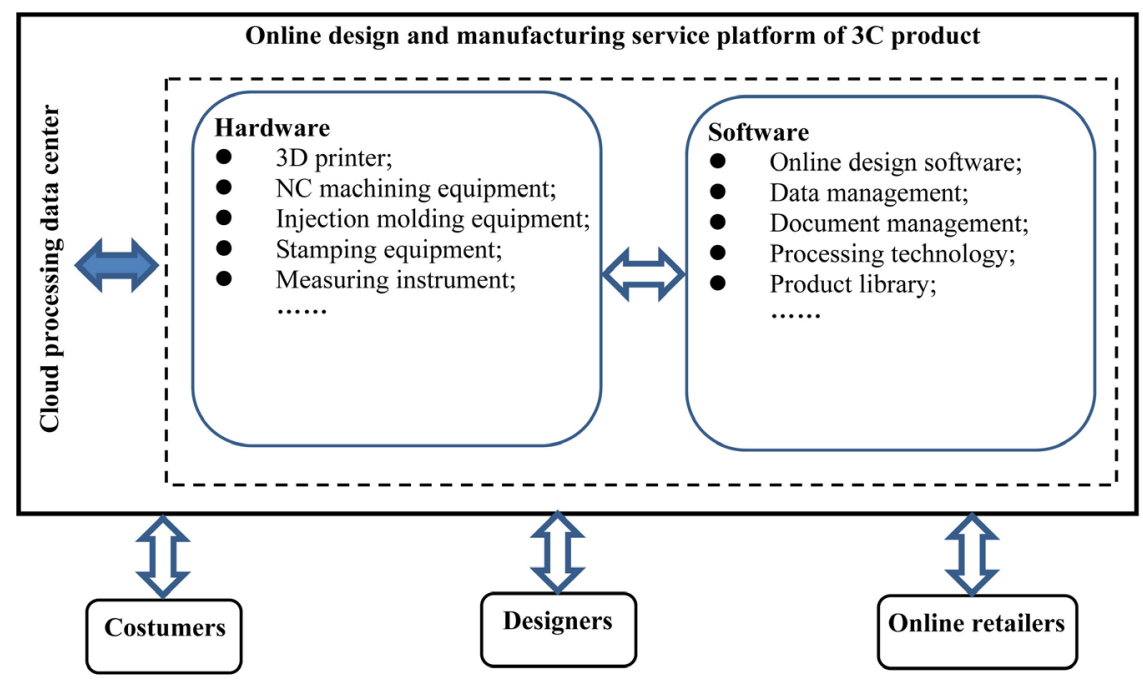

Figure 3. Online design and manufacturing service platform of 3C product. 
cost and rapid upgrading. 3D printing technology is just in line with the characteristics of $3 \mathrm{C}$ product manufacturing industry. Integrating 3D printing into the manufacturing of $3 \mathrm{C}$ products, combining with the internet, big data and other new technologies, the proposed manufacturing system integrated with 3D printer has the following advantages:

1) It can enable consumers to participate in the design and obtain required $3 \mathrm{C}$ products online. In this way, the designed products can better meet the needs of consumers.

2) $3 \mathrm{D}$ printing enables consumers to enjoy complex and personalized $3 \mathrm{C}$ products with lower cost and shorter cycle time.

3) Based on the $3 \mathrm{C}$ product design and manufacturing platform, enterprises can use digital production and management via network and big data, making the whole process more convenient and simpler.

4) The mode can make small batch and single piece production become normal in low cost. It also makes "light luxury + light customization" to be a possibility and trend.

\section{Acknowledgements}

This work was supported by "3C-Product Intelligent Manufacturing Engineering Technology Research and Development Center of Jiangsu Province” from Jiangsu Education Department and "New Driving and Ambient Energy Harvesting Innovation Team Based on Functional Materials" from Suzhou Vocational University.

\section{Conflicts of Interest}

The authors declare no conflicts of interest regarding the publication of this paper.

\section{References}

[1] Analysis Report of China's 3C Industry in 2020-Research on the Present Situation and Development Prospect of Industrial Scale. http://www.chinabaogao.com

[2] Huang, W.D. (2007) Laser Additive Manufacturing. Northwest University of Technology Press, Xi'an.

[3] Chen, X.F. and Sun, C.H. (2015) Application of Reverse Engineering and Rapid Prototyping Technology. China Machine Press, Beijing.

[4] Mohsen, A. (2020) 3D Printing Role in Filling the Critical Gap in the Medical Supply Chain during COVID-19 Pandemic. American Journal of Industrial and Business Management, 10, 988-1001. https://doi.org/10.4236/ajibm.2020.105066

[5] Rayna, T. and Striukova, L. (2014) The Impact of 3D Printing Technologies on Business Model Innovation. In: Benghozi, P., Krob, D., Lonjon, A. and Panetto, H., Eds., Digital Enterprise Design \& Management, Springer, Berlin, 119-132. https://doi.org/10.1007/978-3-319-04313-5_11

[6] Wang, X.Y. and Zhu, L. (2018) 3D Printing and Industrial Manufacturing. China Machine Press, Beijing.

[7] Janssen, G.R., Blankers, I.J., Moolenburgh, E.A. and Posthumus, A.L. (2014) The 
Impact of 3-D Printing on Supply Chain Management. TNO: Innovation for Life, April 2014.

[8] King, R. (2012) 3D Printing Coming to the Manufacturing Space and Outer Space. Bloomberg LP, Bloomberg.

[9] Royte, E. (2013) What Lies Ahead for 3-D Printing? Smithsonian Institute, Washington DC.

[10] Elms, D.K. and Low, P. (2013) Global Value Chains in a Changing World. World Trade Organization, Geneva. https://doi.org/10.30875/0b68ab34-en

[11] Lu, B.H. Additive Manufacturing Is the Future of Manufacturing Research. https://www.hbrchina.org/2016-05-23/4124.html

[12] Attaran, M. (2017) Additive Manufacturing: The Most Promising Technology to Alter the Supply Chain and Logistics. Journal of Service Science and Management, 10, 189-205. https://doi.org/10.4236/jssm.2017.103017

[13] Zhang, L.J., Huang, L.H. and Wang, Y.F. (2016) A Research Report of NC Processing of 3C Industry Products. Manufacturing Technology \& Machine Tool, No. 9, 29-33.

[14] Flexible Automatic Production Line and Its Development Trend, 2016-09-23. http://news.cncaa.org/28210.html 